\title{
BODY BUILD AND PREOPERATIVE ARTERIAL OXYGEN TENSIONS
}

\author{
W.M. WAHBA
}

A REDUCTION of arterial oxygen tension $\left(\mathrm{Pa}_{\mathrm{O}_{2}}\right)$ that is progressive with age has been established. Marshall and Wyche reviewed a number of these reports and present a very convincing regression equation from the data supplied. ${ }^{1}$ "Airway Closure" (AC) which is known to increase with age ${ }^{2}$ can be a contributing factor as can the increase in dispersion of pulmonary blood flow with age as suggested by West. ${ }^{3}$ Obesity is another factor which can promote AC. ${ }^{4}$ It is conceivable, therefore, that a relationship exists between $\mathrm{Pa}_{\mathrm{O}_{2}}$ and weight. This would be particularly significant to anaesthetic practice. The present study was undertaken to determine the existence of such a relationship and to compare it with that known to exist between age and $\mathrm{Pa}_{\mathrm{O}_{2}}$. The effect of barbiturate premedication on $\mathrm{Pa}_{\mathrm{O}_{2}}$ was also re-examined.

\section{METHODS}

Thirty-five surgical patients were studied. Mean age was $47.3 \pm 2.9$ years (range: 20 to 78 ), and mean weight was $72.9 \pm 13.1 \mathrm{~kg}$. (range: 51 to 105). Arterial blood samples were taken from a peripheral artery with the patient lying supine, unpremedicated, and in the fasting state. The samples were drawn anaerobically into heparinized syringes, packed in ice, and analyzed by an Instrumentation Laboratories analyzer (113) equipped with standard electrodes. Linear correlations for $\mathrm{P}_{\mathrm{O}_{2}}$ vs age, weight, and the ratio of weight/height were determined. Blood gases were measured in another group of twenty male patients (aged 46-76 years) who had received pentobarbitone $50-75 \mathrm{mgm}$ by intramuscular injection one hour before anaesthesia.

\section{Results}

These are presented in Figures 1 to 3 . A significant inverse relationship was found for age vs $\mathrm{Pa}_{O_{2}}(\mathrm{r}=-0.69)$. The relationship between weight and $\mathrm{Pa}_{0_{2}}$ was poor $(r=0.25)$ but that for $\mathrm{Pa}_{\mathrm{O}_{2}}$ and weight/height was better $(\mathrm{r}=-0.37)$.

\section{Discussion}

The inverse correlation of $\mathrm{Pa}_{0}$, with age confirms previous reports in the anaesthetic literature. ${ }^{5-9}$ For the sake of comparison, data from these five reports and the present one are shown in Figure 4. Differences between the lines shown are small and probably insignificant.

Although a relationship between weight and $\mathrm{Pa}_{\mathrm{O}_{2}}$ was anticipated, the lack of

From the Department of Anaesthesia, Queen Elizabeth Hospital of Montreal and McGill University. 


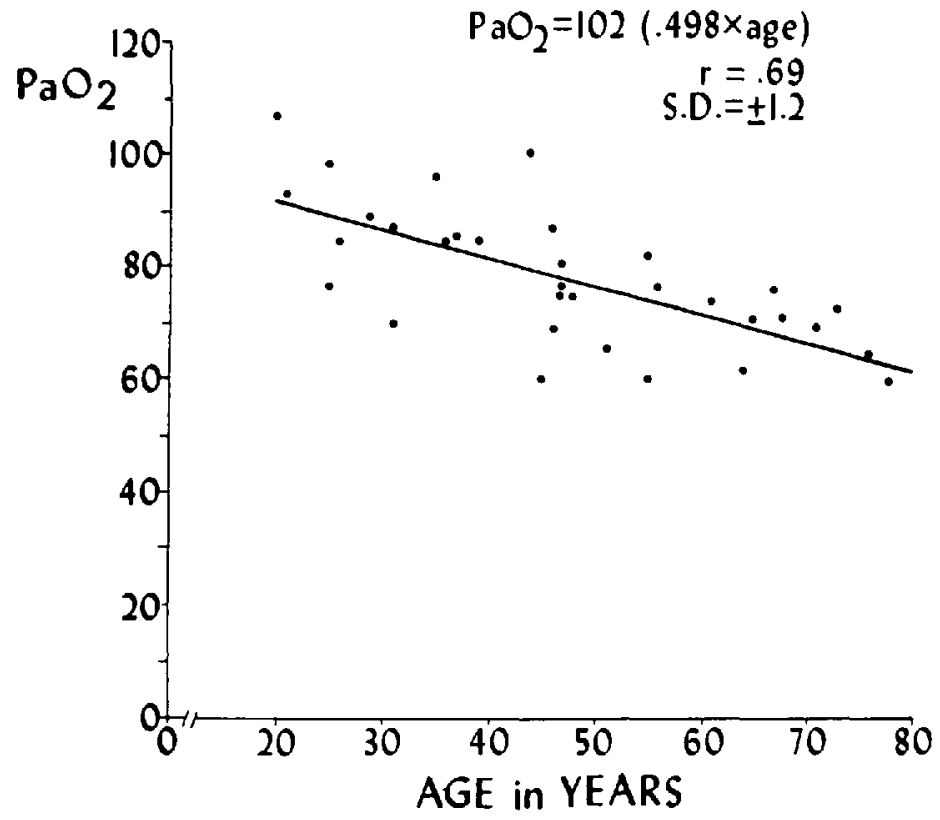

Figure 1. Age (years) and arterial oxygen tensions.

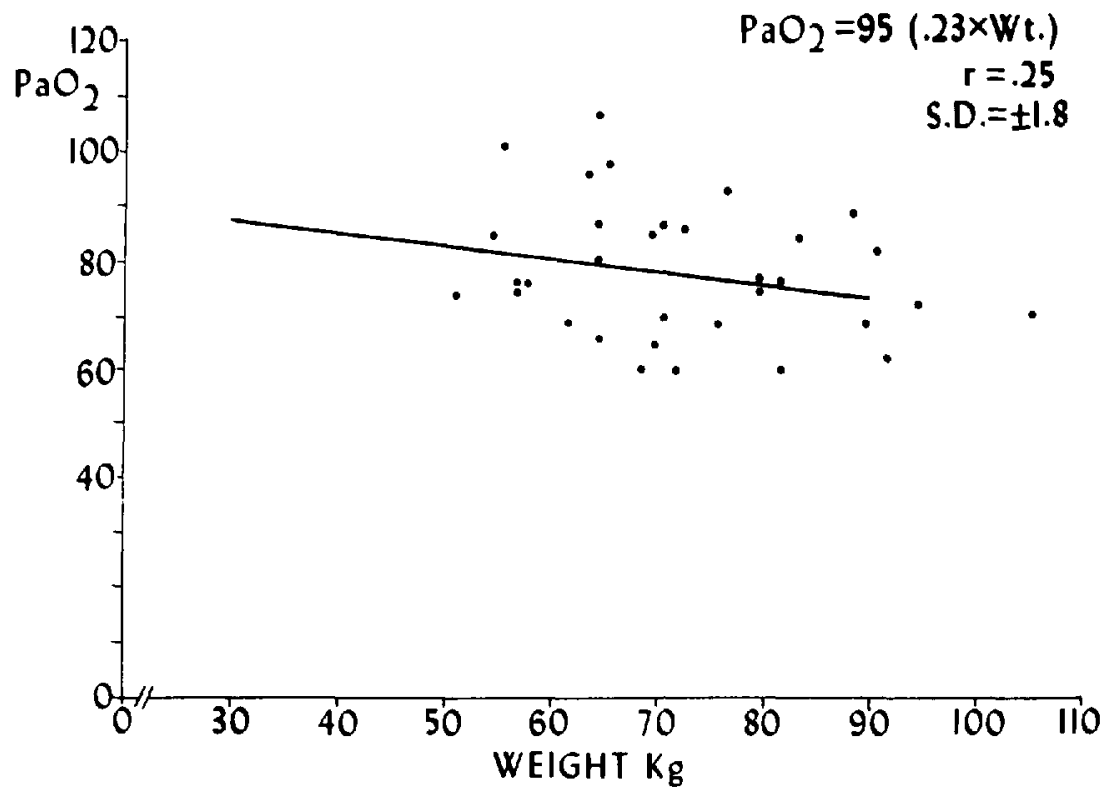

Figure 2. Weight (kilograms) and arterial oxygen tensions. 


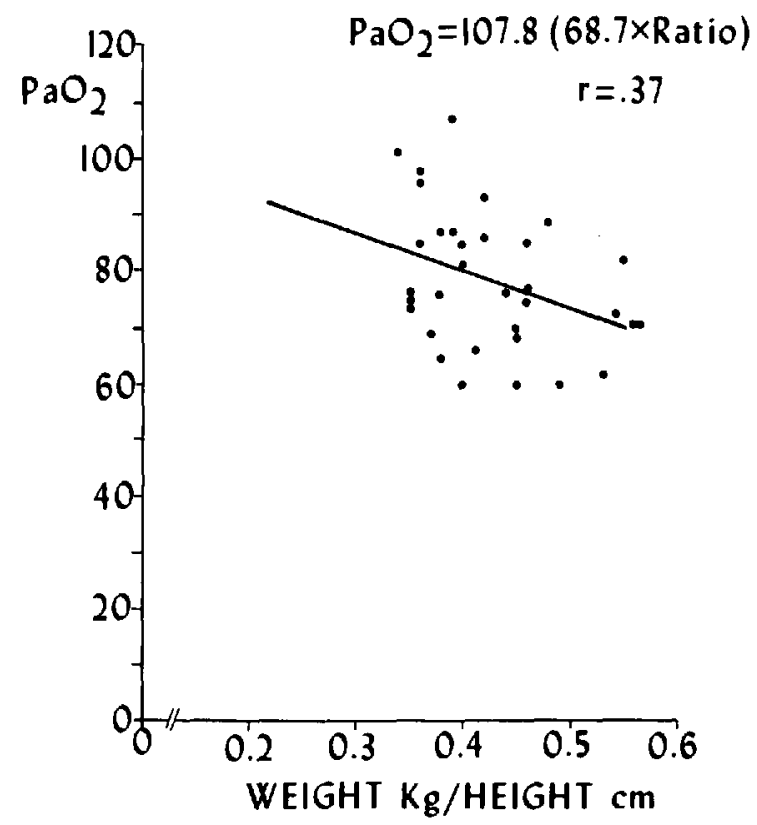

FIGURE 3. Weight/height and arterial oxygen tensions.

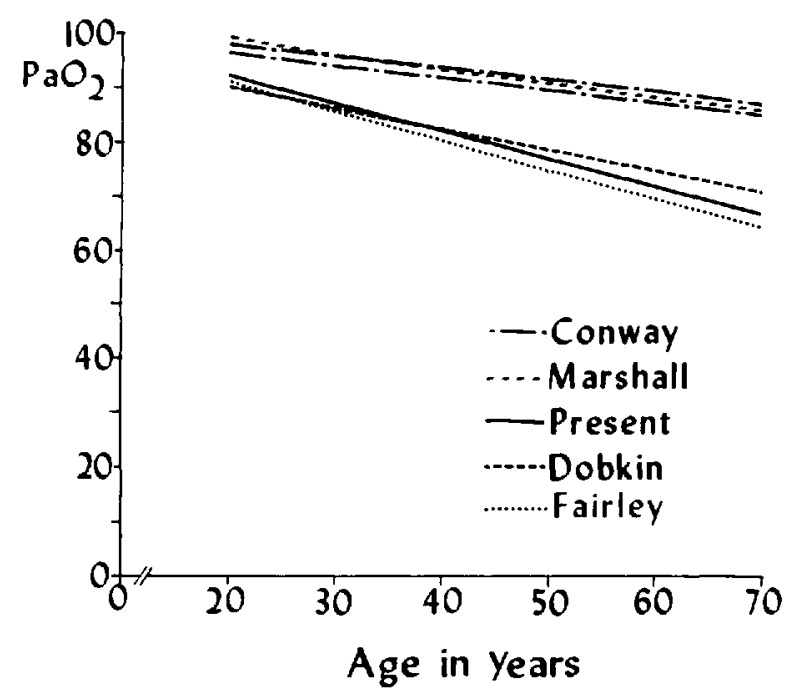

Figure 4. Regression equations for age and arterial oxygen tensions.

significance need not be surprising. It can be explained by two suppositions. The first is the relative absence of airway closure in some of the subjects and the other is the possibility of mild hyperventilation so that $\mathrm{Pa}_{2}$ was little affected. When body build (weight in $\mathrm{kg}$ /height in $\mathrm{cms}$ ) is considered, a more significant relationship is evident. In other words, "body bulk" contributes adversely to $\mathrm{Pa}_{\mathrm{O}_{2}}$. Re- 
ductions in Functional Residual Capacity (FRC) after induction of general anaesthesia are greater with larger weight/height ratios. ${ }^{10}$ The obvious consequence is that relative hypoxaemia may be made worse following induction, should the fall in FRC be large enough to cause an increase in venous admixture secondary to more closure occurring during total ventilation.

There are conflicting reports on the effects of premedication on arterial oxygenation. Tomlin ${ }^{11}$ reported a reduction in $\mathrm{Pa}_{2}$ following atropine, but two other reports deny this. ${ }^{6,8}$ Barbiturates do not seem to have any effect. ${ }^{12,13}$ Morphine on the other hand has been reported to decrease ${ }^{13}$ or have no effect ${ }^{8}$ on $\mathrm{Pa}_{\mathrm{O}_{2}}$.

The $\mathrm{Pa}_{\mathrm{O}_{2}}$ measured following pentobarbitone premedication in our twenty patients were plotted against age (Figure 5). All the points were above the expected $\mathrm{P}_{\mathrm{O}_{2}}$ for that age as determined in the first part of the study. This finding is in agreement with Ravin's report ${ }^{12}$ and can be taken as evidence against a respiratory depressant effect. The data from Wyche, et al. ${ }^{14}$ for 24 patients who had morphine and atropine premedication is plotted on the same graph (open circles). In this case, all the points are around the regression line, with most of them lying above that line. Apparently, therefore, morphine $0.1 \mathrm{mg} / \mathrm{kg}$ does not have significant effects on Pan..

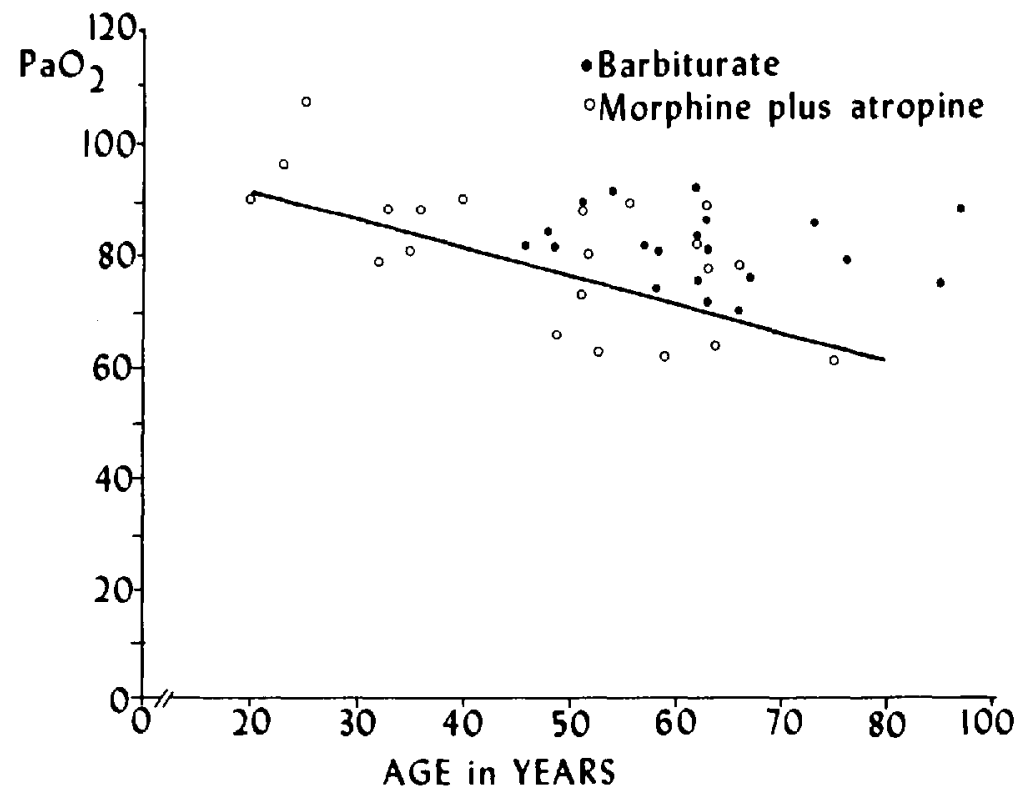

Figure 5. Preoperative $P_{1,2}$ following premedication and age.

\section{Conclusion}

Arterial $\mathrm{P}_{10: 2}$ decreases with age in a linear fashion; the role of weight is not very clear but body bulk seems to have a more definite importance and may be significant under some circumstances.

Premedication with phenobarbitone did not place $\mathrm{Pa}_{0_{2}}$ below the expected $\mathrm{P}_{\mathrm{O}_{2}}$, and this can be taken as evidence against respiratory depression due to barbiturate. The same can be said for morphine $0.1 \mathrm{mg} / \mathrm{kg}$ and atropine $0.5 \mathrm{mgm}$. 


\section{SUMMARY}

Arterial oxygen tensions were determined in 35 supine unpremedicated surgical patients. Correlations were sought for age, weight, and weight/height, and $\mathrm{Pa}_{\mathrm{O}_{2}}$. A definite, clear cut linear reduction of $\mathrm{P}_{\mathrm{O}_{2}}$ with age was found but not for weight alone. A relationship with weight/height ratio was found. If the weight/height related reduction in FRC following induction is added to that, two potential factors can be seen to contribute to intra-operative hypoxaemia.

In a further 20 patients who received phenobarbitone premedication only, arterial oxygen tensions were found to be above the predicted line for their age. This is taken as evidence against respiratory depression due to premedication with barbiturates.

\section{RÉSUMÉ}

La tension arterielle en oxygen fut déterminée chez trente-cinq malades. Tous étaient à jeûne, sans prémedications, et couchés. Un rapport très net de diminution du $P_{O_{2}}$ avec l'age fut trouvé. Les $P_{0_{2}}$ avaient un rapport avec le rapport poids/taille plus évident que celui avec les poids seule. Il a été déja rapporté qu'il y a un rapport très étroit entre la diminution de la Capacité Residuelle Fonctionelle (CRF) et le rapport poids/taille. Donc il semble bien que ces deux facteurs pourraient jouer un rôle dans l'hypoxaemie per-opératoire.

En plus, les $\mathrm{P}_{\mathrm{O}_{2}}$ chez vingt autres malades ayant reçus seulement un barbiturique furent déterminées. Chez tous, la $\mathrm{P}_{\mathrm{O}_{2}}$ était plus élevé que la $\mathrm{P}_{\mathrm{O}_{2}}$ prevus pour leur age, ce qui indique que les barbituriques ne causent pas une dépression respiratoire. La même chose est évidente pour d'autres malades ayant reçues de la morphine $0.1 \mathrm{mgm} / \mathrm{kg}$ et de l'atropine $0.5 \mathrm{mg}$.

\section{ACKNOWLEDGMENTS}

The author wishes to express his gratitude to Dr. R. Martin for help with the statistical analysis and to Miss C. Ciampini for typing the manuscript.

\section{REFERENCES}

1. Marshall, B.E. \& Wyche, M.Q. Hypoxaemia during and after anesthesia. Anesthesiol. 37: 178 (1972).

2. Antronisen, N.R., Danson, J., Robertson, P.C., \& Ross, W.R.D. Airway closure as a function of age. Resp. Physiol. 8: 58 (1969).

3. West, J.B. Blood flow to the lung and gas exchange. Anesthesiol. $41: 124$ (1974).

4. Couture, J., Picken, J., Trop, D., Ruff, F., Lousada, N., Houseley, E., \& Bates, D.V. Airway closure in normal, obese, and anesthetized supine subjects. Fed. Proc. 29: 267 (1970).

5. Conway, C.M., Payne, J.P., \& Tomlin, P.J. Arterial oxygen tensions of patients awaiting surgery. Br. J. Anaesth. 37: 405 (1965).

6. Conway, C.M. \& Payne, J.P. Atropine premedication and arterial oxygen tension. Acta Anaesth. Scand. 10 (suppl. 23): 530 (1966).

7. Marshall, B.E. \& MildaR, R.A. Some factors influencing post-operative hypoxaemia. Anaesthesia 20:408 (1965).

8. Doвkin, A.B., Su, J.P.G., \& Byles, Ph. Normal Pan., and San. in elderly patients and the effects of premedication with atropine and meperidine. Acta Anaesth. Scand. 10 (suppl. 23): 542 (1966). 
9. Fairley, H.B., Kerr, J.H., Laws, A.K., \& Seldehy, G.R. The avoidance of post-operative hypoxaemia: an assessment of three techniques for use during anaesthesia. Can. Anaes. Soc. J. 15: 152 (1968).

10. Don, H.F., Wahba, W.M., Cuadrado, L., \& Kelbar, K. The effects of anesthesia and 100\% oxygen on the functional residual capacity of the lungs. Anesthesiol. 32: 521 (1970).

11. Tomlin, R.J., Conway, C.M., \& Payne, J.P. Hypoxaemia due to atropine. Lancet 1: 14 (1964).

12. Ravin, M.B. Comparison of spinal and general anesthesia for lower abdominal surgery for patients with chronic obstructive pulmonary disease. Anesthesiol. 35: 319 (1971).

13. Pierce, J.A. \& Carofalo, M.L. Preoperative medication and its effects on blood gases. JAMA 194: 487 (1965).

14. Wyche, M.Q., Teichner, R.L., Kallos, T., Marshall, B.E., \& Smith, T.C. Effects of continuous positive-pressure breathing on functional residual capacity and arterial oxygenation during intra-abdominal operations. Anesthesiol. 38: 68 (1973). 